\title{
MEFV and NLRP3 gene variants in children with pfapa syndrome in slovenia
}

\author{
Daša Perko ${ }^{1 *}$, Maruša Debeljak², Nataša Toplak , Tadej Avčin ${ }^{1}$ \\ From 21st European Pediatric Rheumatology (PReS) Congress \\ Belgrade, Serbia. 17-21 September 2014
}

\begin{abstract}
Introduction
PFAPA syndrome is the most common autoinflammatory fever disorder in childhood, characterized by recurrent fever, aphthous stomatitis, pharyngitis and adenitis. Mutations in the $M E F V$ and NLRP3 genes are known to cause syndromes with PFAPA overlapping symptoms (Familial Mediterranean Fever and Cryopyrin-Associated Periodic Syndrome), which are rarely reported in patients from Slovenia.
\end{abstract}

\section{Objectives}

The aim of the study was to assess the frequency of $M E F V$ and NLRP3 gene variants in pediatric patients with PFAPA syndrome from Slovenia in order to determine whether genes involved in other autoinflammatory diseases, might play a role in PFAPA pathogenesis.

\section{Methods}

We collected clinical and laboratory data of PFAPA patients under the age of 5 , who were followed at the University Children's Hospital Ljubljana. All 10 exons of $M E F V$ gene and 9 exons of NLRP3 gene, including intron/ exon regions of both genes were directly sequenced.

\section{Results}

In total, 30 PFAPA patients were tested for $M E F V$ and NLRP3 gene variants. Mean age at the syndrome onset was $2.1 \pm 1.3$ and at diagnosis $4.2 \pm 1.8$ years. $19(63 \%)$ patients were male and $11(37 \%)$ were female. Mean duration of episode was 3.5 days, mean interval between the episodes was 3.5 weeks. Most common symptoms beside fever were pharyngitis and cervical adenitis in $90 \%$ and aphtosis ( always or sometimes) in $63 \%$.
Overall, 10 patients (33\%) were found to have 11 variants, all in heterozygous state. 6 patients have Q703K variant in NLRP3, one E148Q in $M E F V$ and one combination of I591T in MEFV and Q703K in NLRP3. Novel variant in NLRP3, P200T, was identified in one patient. One girl was found to have known variant in NLRP3 gene, S726G, which is associated with CINCA syndrome. This girl has had typical PFAPA symptoms, but she also has epilepsy and mild developmental delay.

\section{Conclusion}

Five different $M E F V$ and NLRP3 gene variants were identified in 10 of 30 PFAPA patients with $M E F V$ variants found in 2 patients and NLRP3 variants in 9. Our results indicate genetic heterogeneity of PFAPA population and possible overlap with other periodic fever syndromes.

\section{Disclosure of interest}

None declared.

\section{Authors' details}

${ }^{1}$ Department of Allergology, Rheumatology and Clinical immunology, UMC Ljubljana, University Children's Hospital Ljubljana, Slovenia. ${ }^{2}$ Unit for Special Laboratory Diagnostics, UMC Ljubljana, University Children's Hospital, Ljubljana, Slovenia.

Published: 17 September 2014

\section{doi:10.1186/1546-0096-12-S1-P81}

Cite this article as: Perko et al:: MEFV and NLRP3 gene variants in

children with pfapa syndrome in slovenia. Pediatric Rheumatology 2014 12(Suppl 1):P81. 